\title{
Kritik Enerji Tesislerinin Deprem Risk Değerlendirmesinde Farklı Hasargörebilirlik Fonksiyonlarının İncelenmesi
}

\author{
A. Can ZÜLFÍKAR ${ }^{* 1}$ ORCID 0000-0001-6610-3334 \\ Seyhan OKUYAN AKCAN ${ }^{2}$ ORCID 0000-0001-6824-8182 \\ Ali YEŞILYURT ${ }^{1}$ ORCID $0000-0002-9442-1687$ \\ Murat ERÖZZ ${ }^{3}$ ORCID $0000-0002-6328-7323$ \\ Tolga CIMILLi ${ }^{3}$ ORCID 0000-0002-8037-9334
}

\author{
${ }^{1}$ Gebze Teknik Üniversitesi, Mühendislik Fakültesi, İnşaat Mühendisliği Bölümü, Kocaeli \\ ${ }^{2}$ Boğaziçi Üniversitesi, Mühendislik Fakültesi, İnşaat Mühendisliği Bölümü, İstanbul \\ ${ }^{3}$ Varlık Yönetimi ve Sürdürülebilirlik, EnerjiSA Üretim, İstanbul
}

Geliş tarihi: 16.07.2021 Kabul tarihi: 10.12.2021

Atıf şekli/ How to cite: ZÜLFIKAR, A.C., AKCAN, S.O., YEŞILIURT, A., ERÖZ, M., CIMILLLI, T., (2021). Kritik Enerji Tesislerinin Deprem Risk Değerlendirmesinde Farkl Hasargörebilirlik Fonksiyonlarının Incelenmesi. Çukurova Üniversitesi, Mühendislik Fakültesi Dergisi, 36(4), 1019-1032.

\section{Özet}

Elektrik enerji tesisleri, deprem tehlikesinden dolayı hasar görme olasılığı yüksek kritik altyapılardan bir tanesidir. Sanayileşmenin yoğun olduğu Marmara bölgesinde çok sayıda elektrik enerji tesisleri bulunmaktadır. Bu çalışma kapsamında açık kaynaklı OpenQuake yazılımı kullanılarak, Marmara bölgesi için olasılıksal deprem tehlike analizi gerçekleştirilmiştir. Deprem tehlike analizinde, SHARE projesi ,2013 Avrupa-Akdeniz sismik tehlike modelinde tanımlanan (ESHM13) kaynak ve yerel zemin etkileri mantık ağacı modelleri ile dikkate alınmıştır. Çalışma kapsamında, Marmara bölgesinde yer alan tipik bir enerji üretim tesisi olan Bandırma-I Doğalgaz kombine çevrim santrali deprem tehlikesi analizi gerçekleştirilmiştir. Elde edilen sonuçlar, 2018-TBDY ve 2007-DBYBHY yönetmeliklerinde bulunan tasarım spektrumları ile karşılaştırılmıştır. Söz konusu tesiste, kritik yapı olan santral kontrol binası için farklı zemin durumu ve farklı hasargörebilirlik fonksiyonlarının dikkate alındığı deprem risk değerlendirmesi yapılmıştır. Marmara bölgesinde meydana gelebilecek olası deprem yer hareketi sonucu, dikkate alınan tesisin maruz kalacağı risklerin tespiti ve bu risklerin azaltılmasına yönelik faaliyetlerin geliştirilebilmesi için son derece kullanışlı olan kayıp eğrileri elde edilmiştir.

Anahtar kelimeler: Olasılıksal deprem tehlike ve risk analizi, Doğalgaz kombine çevrim santrali, Kırılganlık fonksiyonları, Hasargörebilirlik fonksiyonları

\footnotetext{
"Sorumlu yazar (Corresponding author): A. Can ZÜLFIKAR, aczulfikar@gtu.edu.tr
} 


\title{
Investigation of Different Vulnerability Functions in Earthquake Risk Assessment of Critical Energy Facilities
}

\begin{abstract}
Electrical energy facilities are one of the critical infrastructures with a high probability of being damaged due to earthquake hazard. There are many electrical energy facilities in the Marmara region, where industrialization is intense. Within the scope of this study, probabilistic earthquake hazard analysis for the Marmara region was carried out using open source OpenQuake software. In the earthquake hazard analysis, source, and local ground effects as defined in the SHARE project, 2013 "Euro-Mediterranean seismic hazard model (ESHM13)" were considered together with the logic tree models. Within the scope of the study, the earthquake hazard analysis of Bandirma-I Natural Gas combined cycle power plant, which is a typical power generation facility in the Marmara region, was carried out and the results were compared with the Turkish earthquake codes (TSC-2007 and TBDY-2018) design spectra. The earthquake risk assessment was carried out for the power plant control building, which is the critical structure in the facility in question, considering different soil conditions and different vulnerability functions. As a result of possible earthquake ground motions that may occur in the Marmara region, loss curves have been obtained, which are extremely useful for the determination of the potential risks that the considered facility will be exposed to and for the development of risk mitigation activities
\end{abstract}

Keywords: Probabilisitc seismic hazard and risk assessment, Natural gas combined cycle power plant, Fragility functions, Vulnerability functions

\section{GíRiș}

Günümüzde, tüm toplumların enerjiye olan talebi hızla artmaktadır. Buna paralel olarak elektrik tüketimi ihtiyacı da yükselmektedir. Tüm modern ve kritik altyapı sistemlerinin bağımlı hale geldiğ elektrik üretimi ve dağıtımı en önemli ve stratejik unsurlardan biri haline gelmiştir. $\mathrm{Bu}$ nedenle, elektrik üretimi ve dağıtımının afet durumları dahil her koşulda devamlılı̆̆ Elektrik enerji tesisleri, deprem tehlikesinden dolayı hasar görme olasılığı yüksek kritik altyapılardan bir tanesidir. Bu sistemler, üretim tesisleri, iletim ve dağıtım ağı şeklinde 3 ana başlık altında toplanmaktadır. Bu 3 ana sınıfın herhangi bir alt elemanında oluşacak hasar, tüm sistemin aksamasina sebep olabilmektedir $[1,2]$. Bu sistemlerde oluşacak aksaklıklar, modern hayatın sürdürülebilmesi, acil servisler ve çeşitli altyapıların işlevselliğinin devamlılı̆̆ında son derece kritik bir role sahiptir. Elektrik enerji tesisinin, bulunduğu bölgedeki ticari ve endüstriyel faaliyetlerin sürekliliği için başlıca ihtiyaçlardan olmasından dolayı, ekonomik ve sosyal hayat üzerinde doğrudan etkisi olduğu görülmektedir. Geçmiş depremlerden sonra yapilan saha çalışmalarında, elektrik şebekelerinde oluşan yerel hasarlardan dolayı üretim ve dağıtımda aksamalar olduğu ve tamirat/bakım süresi boyunca bu aksaklıkların ilgili bölgelerde devam edebildiği görülmüştür.

11 Mart 2011 yılında Japonya'da meydana gelen Mw 9,0 büyüklüğündeki Tohoku depremi sonucu iki önemli elektrik üretim tesisinde ağır hasarların oluştuğu rapor edilmektedir. Söz konusu hasarların giderilip, elektrik üretiminin tekrar sağlanması için yapılan 6 günlük yenileme çalışmalarının sonucunda tesisin \%90 dolaylarında faaliyete geçmesi sağlanmıştır [3]. Yeni Zelanda'nın Christchurch şehrinde meydana gelen 4 Eylül 2010, Mw 7,1 Darfield (Canterbury), 22 Şubat 2011, Mw 6,3 Christchurch ve 13 Haziran 2011, Mw 6,0 Christchurch depremleri sonucu, transformatörler aracılığı ile gerilimin yüksek formdan alçak forma dönüştürüldüğü, elektrik iletim ve dağıtımın yapıldığı şalt sahasında bulunan; $220 \mathrm{kV} \mathrm{CVT,}$ $66 \mathrm{kV}$ trafo porselen buşingleri, porselen mesnet izolatörlerinde, kesicilerde, pantoğraf ayırıcılarda 
ve kontrol binasında bulunan ekipmanlarda (mekanik-elektrik aksan ve muhteviyat) hafif ve orta hasarlar tespit edilmiştir. Söz konusu tesislerin, 3 deprem ayrı ayrı dikkate alındığında, hemen depremlerden sonraki 6 saatten daha kısa bir sürede yeniden faaliyete geçirilmesi sağlanmıştır [4-7]. 4 Nisan 2010, Mw 7,2 Meksika depremi sonucu, San Diego Gaz ve Elektrik (SDG \& E) Trafo Merkezi'nde bulunan baraların mesnet bağlantılarında, porselen parafudurda, trafo porselen buşinglerinde ve normal ayırıcılarda hasarlar meydana gelmiştir. Söz konusu tesis için kritik elemanların tespit edilmesi ve alternatif güçlendirme çalışmaları araştırılmıştır [8]. M. Shinozuka ve arkadaşları [9] tarafindan Los Angeles Department of Water and Power's (LADWP's) elektrik enerji tesisi için yapılan çalışmada, 47 deprem senaryosu dikkate alınarak elde edilen risk eğrileri ile ekonomik parametreler arasında ilişki kurulmuştur. Benzer şekilde literatürde, elektrik enerji tesislerinin sismik hasar görebilirlik değerlendirmesi için yapılmış farklı yöntem ve yaklaşımların dikkate alındığı çalışmalar mevcuttur [10-14].

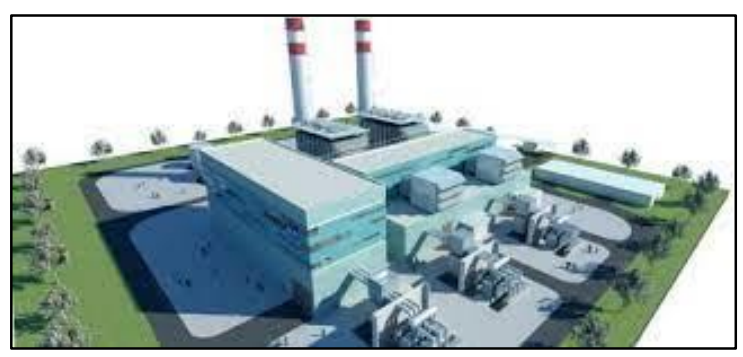

Şekil 1. EnerjiSA Bandırma-I doğalgaz kombine çevrim santrali

Şekil 1'de görülen EnerjiSA Bandırma-I Doğalgaz Kombine Çevrim Santrali, Balıkesir'in Bandırma ilçesinde bulunmaktadır. 936 MW kurulu güce sahip olan santral her biri 304,29 MW kapasiteli iki gaz türbinine, 500 ton/saat buhar kapasiteli iki 1s1 geri kazanımlı buhar jeneratörüne ve 327,6 MW kapasiteli bir buhar türbinine sahiptir. Santral, Marmara Denizi'ne yakın konumlandırılmıştır ve deniz suyu $54.000 \mathrm{~m}^{3} /$ saat miktarı ile soğutma amaçlı kullanılmaktadır. Santralin ulusal elektrik şebekesine bağlantısı $380 \mathrm{kV}$ şalt sahası üzerinden "Bursa DGKÇS" ve "Karabiga" Yüksek Gerilim hatları üzerinden gerçekleşmektedir. Ayrıca doğalgaz santralinin iç ihtiyacını karşılamak üzere 3,45 MW gücünde bir hidroelektrik santral de devreye alınmıştır. Santralin yıllık ortalama enerji üretim kapasitesi 7,9 TWh'dir.

$\mathrm{Bu}$ çalışma kapsamında, üretim kapasitesi ve bileşenlerinin detaylı olarak açıklandığı "EnerjiSA Üretim Bandırma-I Doğalgaz Kombine Çevrim Santrali" için sismik tehlike analizi, söz konusu alanının tektonik yapısı, depremselliği ve sismik kaynak bölgelemesi göz önüne alınarak, açık kaynaklı bir program olan OpenQuake platformunda gerçekleştirilmiştir. Operasyonun ve üretimin devamlılığının sağlanabilmesi için en önemli yapılardan biri olan kontrol binasına ait mali kayıp değerlendirilmesinde, olasıllksal sismik risk değerlendirilmesi, "Kırılganlık Eğrileri”" aracılığ ile yapısal hasarı ele alarak değerlendirilmiştir. $\mathrm{Bu}$ değerlendirmeler ışığında 3 farklı hasargörebilirlik eğrisi kullanılarak çeşitli deprem senaryolarında kontrol binasında oluşabilecek olasılıksal hasar maliyetleri hesaplanmıştır. Farklı hasargörebilirlik fonksiyonlarından elde edilen ekonomik kayıplar ayrı ayrı değerlendirilmiştir. Yapılan çalışmalar, deprem sonrası eylem planlarının geliştirilebilmesi, risk değerlendirme ve azaltma çalışmaları, santralin reasürans değerlendirmesi için son derece önemli sonuçlar vermiştir.

\section{MATERYAL VE YÖNTEM}

Depremlerin neden olduğu yıkıcı etkilerin azaltılması için sismik risk değerlendirmesi ve kayıp tahmini temel ön koşuldur [15]. Bu analizleri gerçekleştirmek için, güvenilir bir sismik tehlike modeline, kapsamlı bir yapı envanter modeline ihtiyaç duyulmakta ve bir dizi kırılganlık ve kayıp fonksiyonlarını kullanmak gerekmektedir [15]. Sismik risk değerlendirilmesi sonucunda, kayıp oranlarının dağılımı veya kauıpların aşma olasılığı hesaplanmaktadır.

Küresel Deprem Modeli (GEM), dünya çapında deprem riskini hesaplamayı amaçlamaktadır [16]. $\mathrm{Bu}$ amaca yönelik sismik tehlike ve risk değerlendirmesi için açık kaynaklı OpenQuake yazılımını geliştirmiştir. OpenQuake projesi, Küresel Deprem Modelinin (GEM- 
http://www.globalquakemodel.org) [17] bir parçası olarak başlatılmıştır. Bu yazılım, hedef bir bölge için senaryo bazlı veya olasılıksal sismik tehlike analizi sonucunda oluşabilecek fiziki ve sosyoekonomik kayıpları hesaplayabilen bir dizi hesaplayıcıdan oluşur. OpenQuake, Python programlama dilinde yazılmış açık kaynaklı, deprem tehlike ve riskini modellemek, araştırmak ve yönetmek için entegre bir ortam sunacak olan web tabanlı bir sismik değerlendirme platformudur [16].

Sismik tehlikenin belirlenmesinde bölgenin tektonik yapısı, deprem oluşumları ve yerel zemin şartları hesaba katılmaktadır. Bölgeye ait sismik veriler ile bölgede kullanilabilecek yer hareketi tahmin denklemleri, olasılıksal tehlike analizi modelini oluşturmaktadır. Deterministitk veya olasılıksal deprem tehlike analizlerinden elde edilen sonuçlara bağlı olarak sismik risk değerlendirilmesi yapilabilmektedir.

Olasılıksal Sismik Tehlike Değerlendirmesinin (OSTA-Probabilistic Seismic Hazard Assessment PSHA) temel bileşenleri; deprem kaynak(lar)ının tanımlanması, her bir kaynak için deprem oluşum karakteristikleri ve yer hareketleri tahmin denklemleridir. $\mathrm{Bu}$ temel bileşenler, belirli bir bölgedeki farklı yer hareketi parametrelerinin aşılması ihtimalini elde etmek üzere olasılığa dayalı bir modele sayısal olarak entegre edilir [18]. Olasılıksal sismik tehlike analizi, tehlikenin olasılıklı bir tanımına dayalı olarak, tek bir varlık için kayıp olasılığı ve kayıp istatistiklerinin hesaplanmasını sağlamaktadır [16]. $\mathrm{Bu}$ hesaplayıcının çıktısı, örneğin risk azaltma çabalarının önceliklendirilmesi için kullanılabilen, farklı yerlerdeki varlıklar arasında karşılaştırmalı risk değerlendirmesi için kullanılmaktadır. OpenQuake platformunda yapılan tehlike analizi sonucunda tehlike eğrileri, spektrumlar ve tehlike haritaları elde edilirken, risk analizi sonucunda kayıp ve hasar dağılımı hesaplanmaktadır. OpenQuake platformu, sismik tehlike ve riskin hesaplanması için dünyadaki çeşitli kurumlar ve araştırma projeleri tarafından test edilmektedir. (Avrupa Komisyonu tarafindan finanse edilen SHARE projesinde, www.share-eu.org'da Avrupa için tehlikenin hesaplanması gibi) [16]. Şekil 2 ile olasılıklı sismik tehlikeye bağlı olasılıklı sismik risk analizi akış şeması gösterilmiştir.

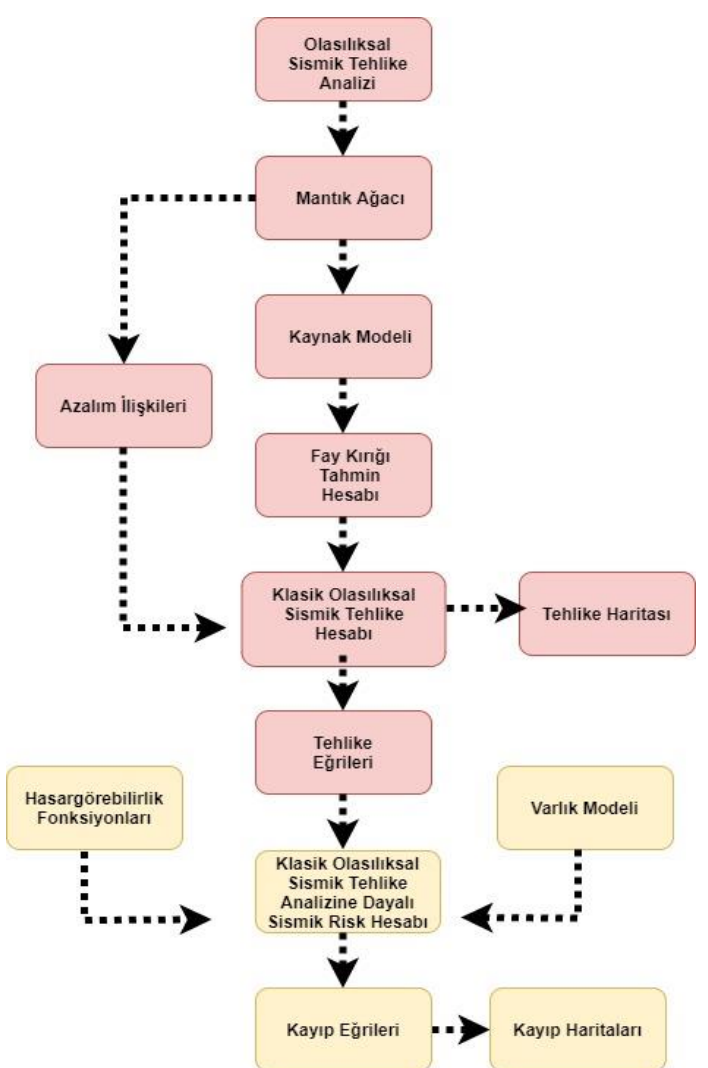

Şekil 2. Klasik olasılıklı sismik tehlikeye dayalı deprem risk hesabı akış şeması

OpenQuake, Klasik OSTA tabanlı hasar hesaplayıcısı, varlığgn belirli bir süre içinde hasar dağılımını vermek için, varlığın bulunduğu yerde sismik tehlike eğrisi ile bir varlık için ayrı veya sürekli hasar durumu kırılganlık fonksiyonlarını sayısal entegrasyon yoluyla birleştirir. Sürekli kırılganlık fonksiyonları, lognormal dağılımın kümülatif dağılım fonksiyonu ile hesaplanmaktadır.

Sismik kırılganlık ve kayıp model değerlendirmesi, olasılıksal sismik riskin değerlendirilmesinde önemli bir adımdır [15]. Kırılganlık, bir dizi sismik yoğunluk ölçüm seviyesine (PGA,Sa) karşılık gelen hasar sınır durumunu aşma olasılığı olarak tanımlanır. Bir kırılganlık modeli ortalama ve standart sapma ile temsil edilen, lognormal 
dağılımlı bir fonksiyondur. Risk analizinde, kırılganlık modeli, hasar dağılımını hesaplamada kullanılmaktadır. Ayrıca, kırılganlık modelleri, belirlenmiş sonuç modelleriyle kullanılarak hasargörebilirlik eğrisi elde etmede kullanılmaktadır. Kırılganlık modelleri, ayrık noktalarla ya da devamlı fonksiyon olarak tanımlanabilmektedir.

Sismik yoğunluk boyunca kayıp oranının olasılıklı dağılımı, kayıp fonksiyonlarıyla tanımlanmaktadır. Hasargörebilirlik eğrisi, yapıda oluşan hasarın oranını ifade ederken, kırılganlık eğrileri dikkate aldığımız herhangi bir hasar durumunun aşılma olasılığını ifade eder. Hasargörebilirlik eğrileri; kırılganlık eğrilerinin sonuç modelleriyle (consequence models) birlikte kullanılmasıyla elde edilebilmektedir [16]. OpenQuake platfromunun mevcut sürümünde ayrık olarak tanımlanan kayıp fonksiyonları, ölümler veya onarım maliyetleri gibi olabilecek kayıpları doğrudan modellemek için kullanılır [15]. Sismik yoğunluk seviyesine (PGA, PGV, Sa) denk gelen ortalama kayıp oranı ve bu orana ait varyasyon katsayısı kullanılarak olasılıklı dağılım olarak OpenQuake platformunda kayıp eğrileri tanımlanabilmektedir.

$\mathrm{Bu}$ çalışmada, açık kaynaklı bir program olan OpenQuake ile çalışma bölgesinin, tektonik yapısı, depremselliği ve sismik kaynak bölgelemesi göz önüne alınarak, Bandırma-I DGKÇS kontrol binası için olasılıklı sismik tehlike analizi gerçekleştirildi. Deprem tehlike analizi sonuçları kullanılarak, hedef yapıda kayıp değerlendirilmesinde, olasılıksal sismik risk analizi gerçekleştirilmiştir. Sismik risk değerlendirilmesinde, üç farklı hasargörebilirlik fonksiyonu kullanılarak kayıplar hesaplanmıştır.

Çalışma kapsamında, sahaya özel olasılıksal deprem tehlike analizi yapılmış, elde edilen spektrum, DBYBHY 2007 [19] ve TBDY2018 [20] tasarım spektrumlarıyla karşılaştırılmıștır. Tasarım ivme veri setinin belirlenmesinde, sahaya özel tehlike analizi spektrumları kullanılmıştır. Gerek zemin ve gerekse yakın fay etkilerini göz önüne alarak belirlenmiş olan sahaya özgü, \%5 sönümlü spektrum eğrileri ile 2018 Türkiye Bina Deprem Yönetmeliği kapsamında yer alan tasarım esaslı, yatay davranış spektrumları 475 ve 2475 yıllık ortalama tekrarlanma periyotları için hesaplanmıştır. TBDY2018 [20]'e göre deprem düzeyleri tekrarlanma periyoduna göre;

- DD-1=50 yılda aşılma olasılığı \%2 (tekrarlanma periyodu 2475 yil) olan deprem yer hareketi düzeyi

- DD-2=50 yılda aşılma olasılığı \%10 (tekrarlanma periyodu 475 y1l) olan deprem yer hareketi düzeyi

- DD-3=50 y1lda aşılma olasılığ $\% 50$ (tekrarlanma periyodu 72 yil) olan deprem yer hareketi düzeyi

- DD-4=50 yılda aşılma olasılığ $\% 68$ (tekrarlanma periyodu 43 yil) olan deprem yer hareketi düzeyi

olarak sınıflandırılmıştır. Şekil 3'te TBDY2018 tasarım spektrumu gösterilmiştir. Spektrum detayları TBDY2018 [20], 2.bölümde anlatılmaktadır.

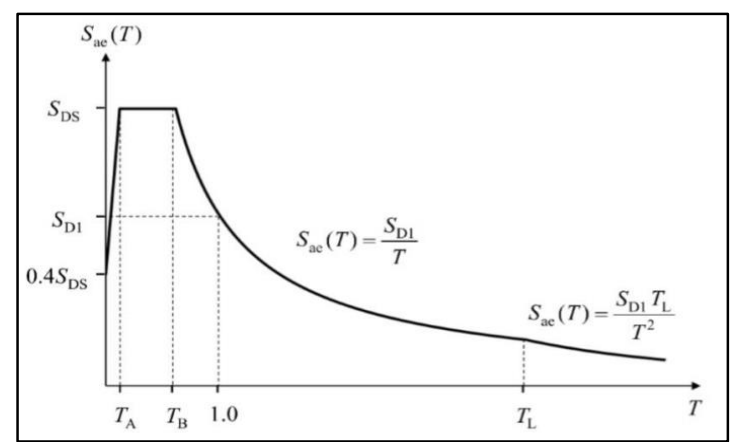

Şekil 3. TBDY 2018 [20] - \%5 sönümlü yatay elastik tasarım ivme spektrumu [20]

\section{BULGULAR VE TARTIŞMA}

\subsection{Marmara Bölgesi Deprem Tehlike Analizi}

OpenQuake platformunda, risk hesap akıș şeması olarak senaryoya dayalı risk analizi, klasik olasılıklı risk analizi ve(veya) olaya bağlı olasılıklı risk analizi bulunmaktadır. OpenQuake platformunda, Marmara bölgesi ve Bandırma-I DGKÇS kontrol binasının bulunduğu konum için olasılıksal deprem tehlike analizi hesabı gerçekleştirildi. Çalışma kapsamında, SHARE projesinde ESHM13 
modelinde [21] tanımlanan, alan kaynak, çizgi kaynak ve arka plan kaynak modelleri dikkate alınmıştır. Sismik tehlikeyi tanımlamak için yer hareketi tahmin denklemleri (YHDT) olarak Chiou\&Youngs (2008) [22] modeli kullanılmıştır. 50 y1llık süre için sismik tehlike analizleri gerçekleştirildi. Zemin bağımlı ve zemin bağımsız olmak üzere iki farklı olasılıksal sismik tehlike analizi gerçekleştirildi. Zemin bağımsız durum için $30 \mathrm{~m}$ derinlikte zemin kayma hızı $\left(\mathrm{V}_{\mathrm{s}, 30}\right) 760 \mathrm{~m} / \mathrm{s}$ olarak tanımlandı. Zemin bağımlı durum için $30 \mathrm{~m}$ derinlikte zemin kayma hızı $\left(\mathrm{V}_{\mathrm{s}, 30}\right) 360 \mathrm{~m} / \mathrm{s}$ olarak tanımland. NEHRP [23] zemin sinıflandirması referans alınarak, $V_{\mathrm{s}, 30}=760 \mathrm{~m} / \mathrm{s}$ değeri $\mathrm{ZB}$ zemin sınıfı, $V_{s, 30}=360 \mathrm{~m} / \mathrm{s}$ değeri $\mathrm{ZD}$ zemin sınıfı olarak dikkate alınd. OpenQuake platformunda gerçekleştirilen, olasılıklı sismik tehlike analizi sonucunda, Marmara bölgesinde, PGA dağılımları, 475 yıl ve 2475 yıl dönüş periyotlu deprem yer harekti düzeyi için irdelenmiştir. Olasılıksal sismik tehlike analizi sonucunda zemin bağımsız durum için 475 yıl ve 2475 yıl dönüş periyotlu deprem yer hareketi düzeyine ait PGA dağılımı sırasıyla Şekil 4-5'te verilmiştir.

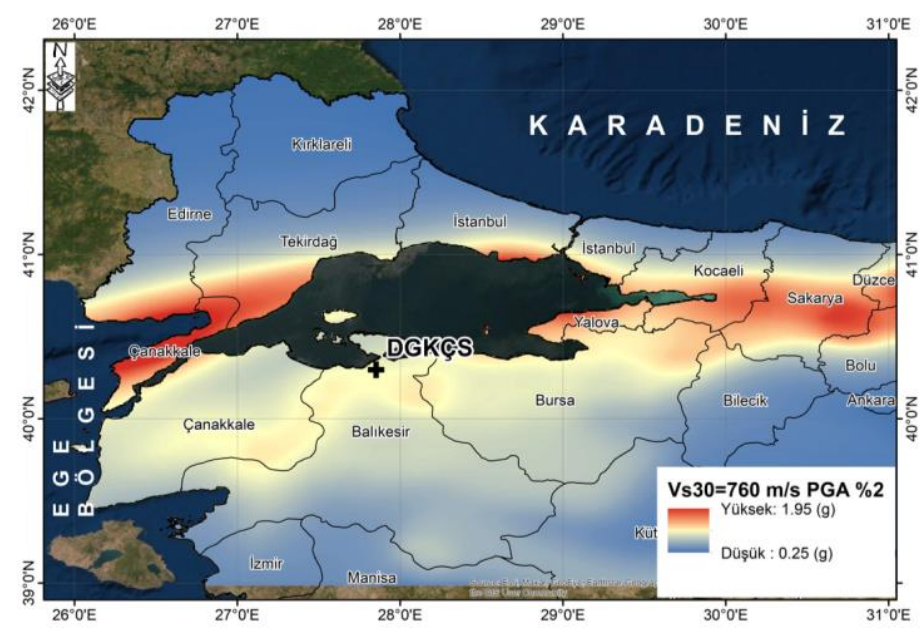

Şekil 4. Marmara Bölgesi için 50 yılda aşılma olasılığ $\% 2$ olan (2475 y1l) deprem yer hareketi düzeyine ait PGA Dağılımı $\left(\mathrm{V}_{\mathrm{s}, 30}=760 \mathrm{~m} / \mathrm{s}\right)$

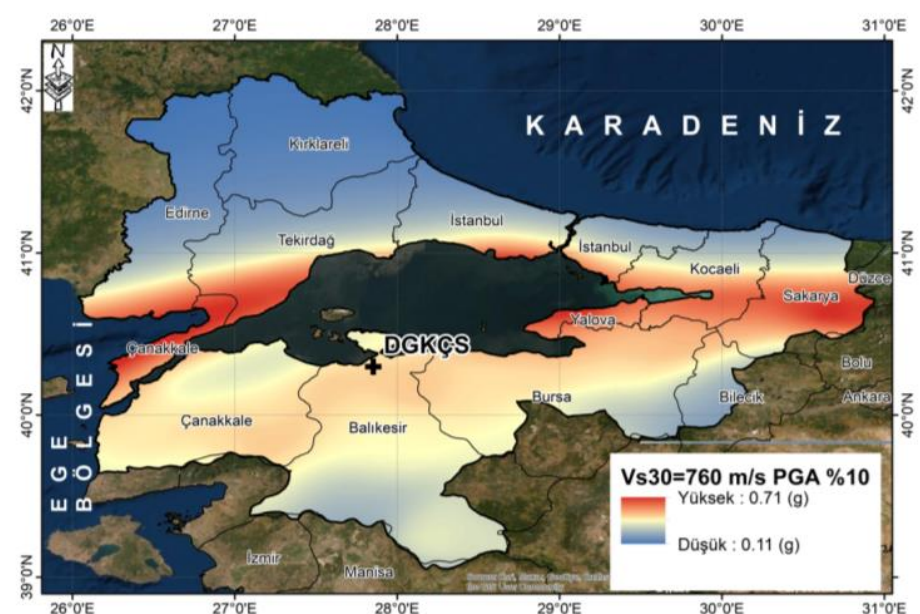

Şekil 5. Marmara Bölgesi için 50 yılda aşılma olasılı̆̆ $\% 10$ olan (475 yıl) deprem yer hareketi düzeyine ait PGA Dağılımı $\left(\mathrm{V}_{\mathrm{s}, 30}=760 \mathrm{~m} / \mathrm{s}\right)$ 
Benzer şekilde, olasılıklı sismik tehlike analizi sonucunda, zemin bağımlı durum için 475 yıl ve 2475 yıl dönüş periyotlu deprem yer hareketi düzeyine ait PGA dağılımı sırasıyla Şekil 6-7’te verilmiştir.

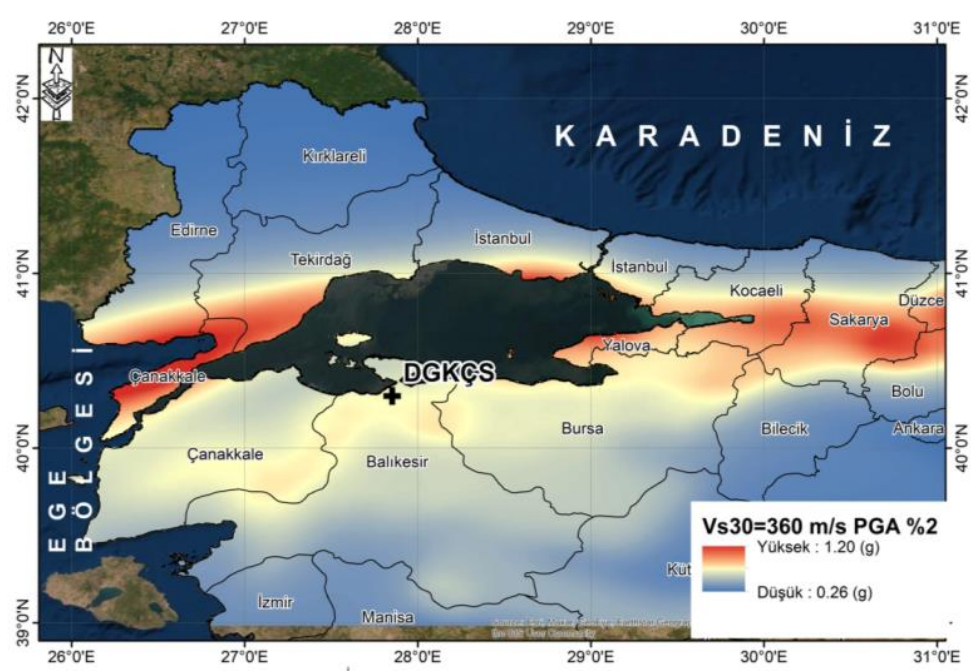

Şekil 6. Marmara Bölgesi 50 yılda aşılma olasılığı \%2 olan (2475 yıl) deprem yer hareketi düzeyine ait PGA Dağ $111 \mathrm{~m} ı\left(\mathrm{~V}_{\mathrm{s}, 30}=360 \mathrm{~m} / \mathrm{s}\right)$

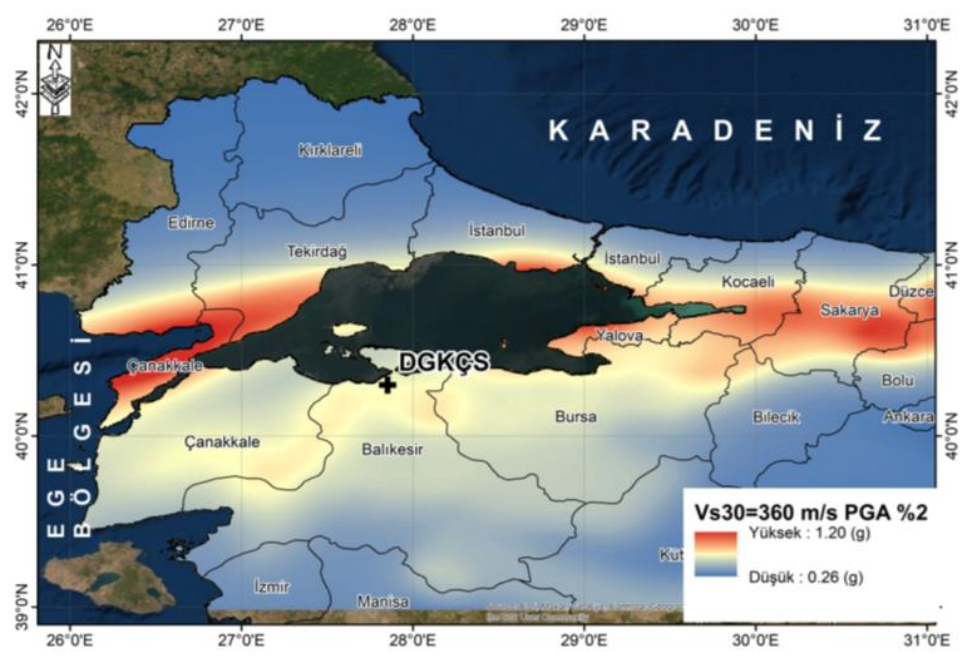

Şekil 7. Marmara Bölgesi 50 yılda aşılma olasılığı \%10 olan (475 y1l) deprem yer hareketi düzeyine ait PGA Dağılımı $\left(\mathrm{V}_{\mathrm{s}, 30}=360 \mathrm{~m} / \mathrm{s}\right)$

Bandırma-I DGKÇS'nin konumunda yumuşak zemin olduğu tespit edilmiştir. Bölgeye ait zemin çalışmalarında $\mathrm{V}_{\mathrm{s}, 30}=360 \mathrm{~m} / \mathrm{s}$ olarak belirlenmiştir. Zemin bağımlı durum için $30 \mathrm{~m}$ derinlikte zemin kayma hızı $\left(\mathrm{V}_{\mathrm{s}, 30}\right) \quad 360 \mathrm{~m} / \mathrm{s}$ olarak kullanıldı. NEHRP [23] zemin sinıflandırmasına göre $\mathrm{V}_{\mathrm{s}, 30}$ değeri ZD zemin sınıfı olduğunu göstermektedir. Şekil 8'de gösterildiği gibi logaritmik olarak Bandırma I 'e ait zemin bağımlı $\left(\mathrm{V}_{\mathrm{s}, 30}=360 \mathrm{~m} / \mathrm{s}\right)$ ve zemin bağımsı $\left(\mathrm{V}_{\mathrm{s}, 30}=760 \mathrm{~m} / \mathrm{s}\right)$ durum için sismik tehlike eğrileri elde edildi. 


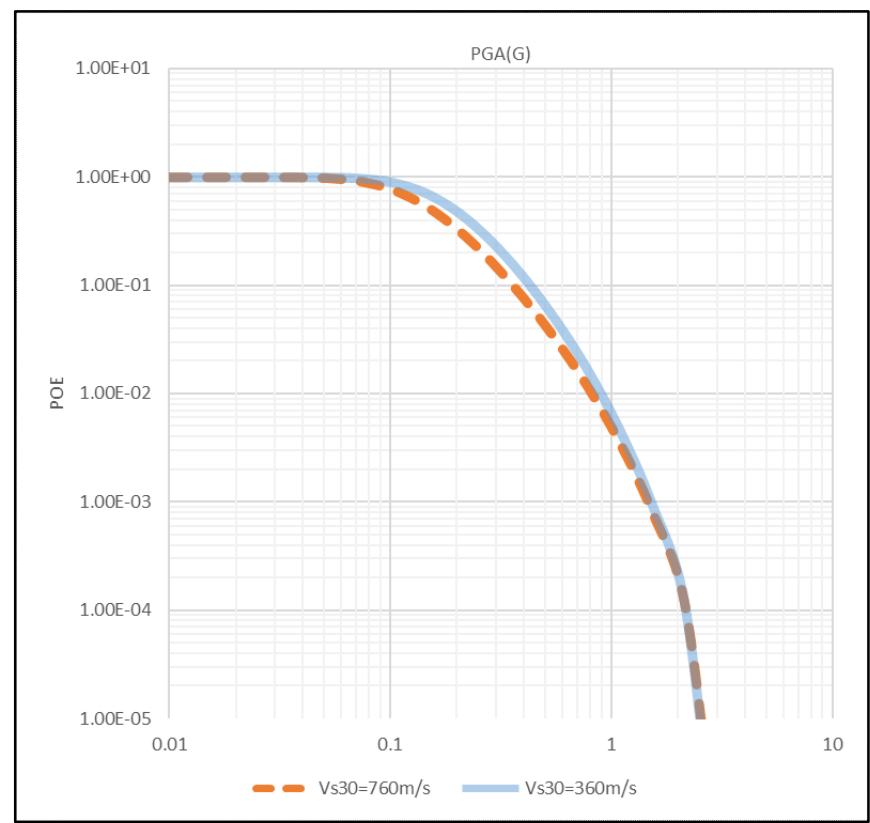

Şekil 8. Zemin bağımlı ve zemin bağımsız durum için Bandırma-I DGKÇS'e ait tehlike eğrileri

Olasılıksal deprem tehlike analizi sonucunda, Bandırma-I DGKÇS kontrol binası için zemin bağımlı ve zemin bağımsız durum için tehlike spektrum eğrisi, deprem tekrarlanma periyodu (475 yıl ve 2475 yıl) için elde edildi. Şekil 9-10'da Bandırma-I DGKÇS kontrol binası için her bir deprem tekrarlanma periyoduna göre iki farklı zemin durumu için elde edilen spektrum eğrileri gösterilmiştir.

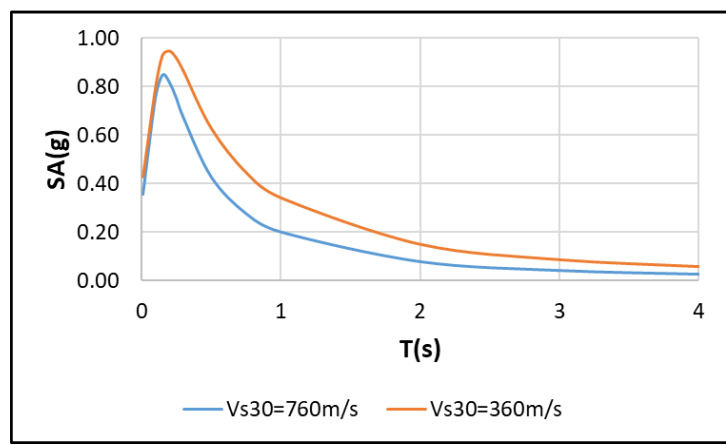

Şekil 9.Zemin bağımlı ve zemin bağımsız durumlarına ait Bandırma-I DGKÇS kontrol binasının bulunduğu yere ait spektrum eğrileri (475yıl tekrarlanma periyodu)

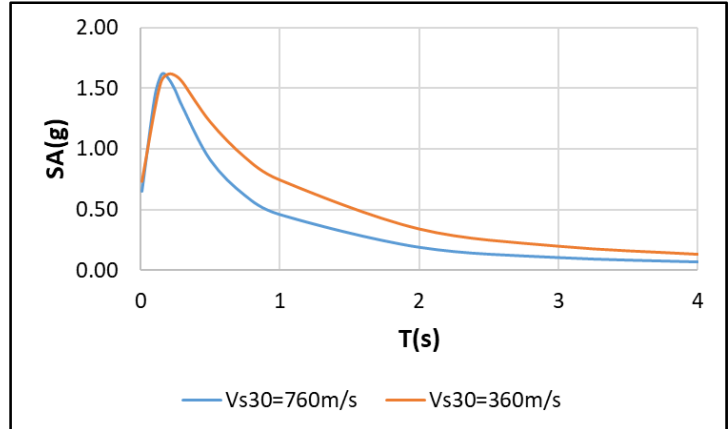

Şekil 10. Zemin bağımlı ve zemin bağımsız durumlarına ait Bandırma-I DGKÇS kontrol binasının bulunduğu yere ait spektrum eğrileri (2475 yıl tekrarlanma periyodu)

Elde edilen sahaya özel spektrum eğrileri, \%5 sönümlü DD1, DD2 deprem düzeylerine ait TBDY 2018 [20]'de ifade edilen spektrumlar ile DBYBHY2007 [19]'de birinci derece deprem bölgesi için sunulan tasarım spektrumları dikkate alınarak, karşılaştırmalı incelemesi sırasıyla, Şekil 11 ve Şekil 12' de gösterilmiștir. Yapılan bu karşılaştırmada, yönetmeliklerde sunulan, zemin bağımlı duruma (ZD zemin sınıfına) ait ve zemin 
bağımsız duruma (ZB zemin sınıfına) ait spektrumlar dikkate alınmıştır. Spektrum hesabında, Uzaklık, fay tipi ve derinlik gibi deprem bilgileri ve istasyon bilgileri parametreleri kullanılmıştır.

Şekil 11-12'de gösterildiği gibi ZD $\left(\mathrm{V}_{\mathrm{s}, 30}=360 \mathrm{~m} / \mathrm{s}\right)$, $\mathrm{ZB}\left(\mathrm{V}_{\mathrm{s}, 30}=760 \mathrm{~m} / \mathrm{s}\right)$ zemin koşullarında, sahaya özel sismik tehlike analizinden elde edilen spektrum, DD1- ve DD-2 deprem düzeyi için TBDY 2018 spektrumu ve birinci derece deprem bölgesi için DBYDBH2007 tasarım spektrumuyla karşılaştırılmıştır.

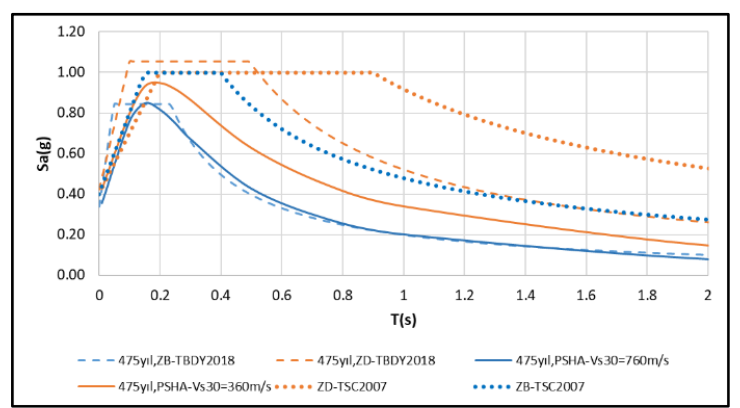

Şekil 11. 475 yıl dönüş periyot deprem için $(\mathrm{DD}-2), \quad \mathrm{ZB}\left(\mathrm{V}_{\mathrm{s}, 30}=760 \quad \mathrm{~m} / \mathrm{s}\right) \quad$ ve $\mathrm{ZD}\left(\mathrm{V}_{\mathrm{s}, 30}=360 \mathrm{~m} / \mathrm{s}\right)$ zemin koşulları için sahaya özel tehlike spektrumlarının TBDY 2018 ve DBYBHY 2007 spektrumlarıyla karşılaştırılması

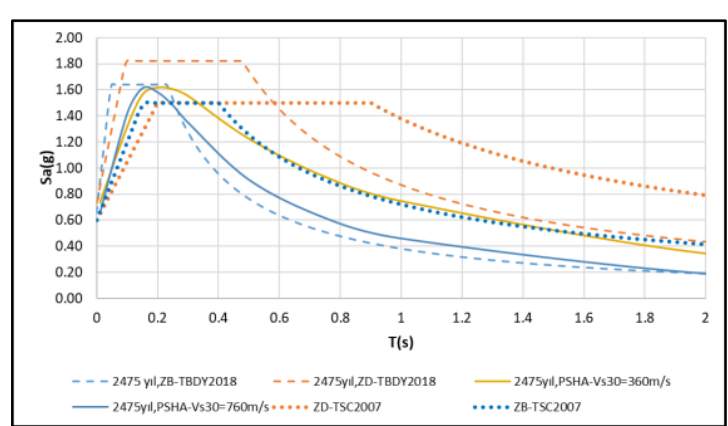

Şekil 12. 2475 yıl dönüş periyot deprem için $(\mathrm{DD}-1), \quad \mathrm{ZB}\left(\mathrm{V}_{\mathrm{s} 30}=760 \quad \mathrm{~m} / \mathrm{s}\right) \quad$ ve $\mathrm{ZD}\left(\mathrm{V}_{\mathrm{s} 30}=360 \mathrm{~m} / \mathrm{s}\right)$ zemin koşulları için sahaya özel tehlike spektrumlarının TBDY 2018 ve DBYBHY 2007 spektrumlarıyla karşılaştırılması
DD-1 seviyesinde deprem için, ZB zemin şartlarında, sahaya özel spektrum TBDY2018 spektrumu ve DBYBHY 2007 ile uyumlu olduğu gözlenmiştir. ZD zemin şartlarında TBDY2018 spektrumu, sahaya özel spektrumdan daha yukarı seviyede kalırken, DBYBHY2007 spektrumu daha aşağı seviyede kalmaktadır. DD-1 deprem seviyesinde, ZB zemin koşulu için olasılıksal sismik tehlike analizi sonucunda elde edilen spektrum, sismik tasarımda kullanılması geçerli olurken, ZD zemin koşulları için bölgede TBDY2018 tasarım spektrumunun kullanılması gerekmektedir.

DD-2 seviyesinde deprem için, ZB zemin şartlarında sahaya özel spektrum TBDY2018 spektrumu ile uyumlu olurken, DBYBHY 2007 spektrumundan aşağı seviyede kalmaktadır. ZD zemin şartlarında TBDY2018 ve DBYBHY2007 spektrumu, sahaya özel spektrumdan daha yukarı seviyede kalmaktadır. DD-2 deprem seviyesi, ZB zemin koşulu için olasılıksal sismik tehlike analizi sonucunda elde edilen spektrum, sismik tasarımda kullanılması geçerli olurken, ZD zemin koşulları için bölgede TBDY2018 tasarım spektrumunun kullanılması gerekmektedir.

Bandırma-I DGKÇS kontrol binası için yapılacak olan olasılıksal sismik risk değerlendirilmesine bağlı olarak hesaplanacak olan ekonomik kayıp tahmininde, olasilıksal sismik tehlike analizinden elde edilen sismik tehlike eğrisi dikkate alınacaktır.

\subsection{Bandırma-I DGKÇS Kontrol Binası, Deprem Risk Değerlendirme Analizi}

Bir Enerji Santrali'nde doğal afetler sonrasında da üretimin devamlılığının sağlanabilmesi için en kritik yapılardan birisi de Santral Kontrol Bina'sıdır. Santralin tüm üretim süreci bu binadaki Kontrol Odası'ndan takip edilir ve yönetilir.

Çalışma kapsamında dikkate alınan mevcut Kontrol Binası, 42,1 m X 22,6 m boyutlarında, iki katlı, betonarme karkas bir yapı olarak tasarlanmıştır. Bina taşıyıcı sistemi betonarme çerçeveler ve perdelerden oluşacak şekilde düzenlenmiştir (Şekil 13). 


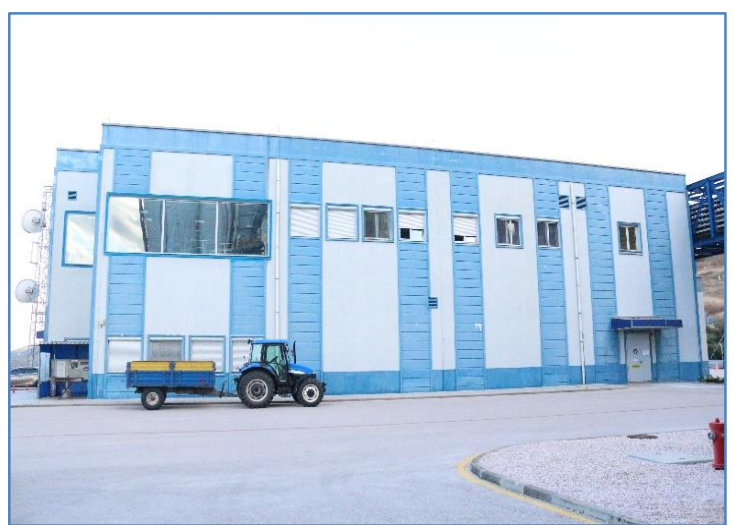

Şekil 13. EnerjiSA Bandırma-I DGKÇS kontrol binası genel görünüş

Kontrol Bina'ları, kontrol odasının yanı sıra, Enerji Santrallerinde üretimin devamlılı̆̆ için çok önemli olan C\&I odası, akü odası, düşük/orta gerilim odaları vb. kritik ekipman odalarını muhteva eder (Şekil 14). Bu bina, santralin ana kontrol merkezidir. Sahaya giden tüm sinyal ve enerji kabloları bu binada toplanmaktadır.

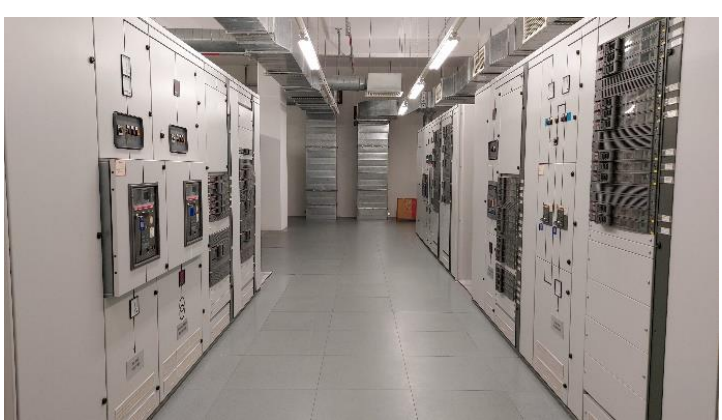

Şekil 14. EnerjiSA Bandırma-I DGKÇS kontrol binası, düşük gerilim odası

Bu çalışmada dikkate alınan herhangi bir deprem tehlikesi için yapıda oluşacak hasar dağılımlarının değerlendirilmesinde, Hazus [24]'da sünek az katlı özel betonarme yapılara ait hafif, orta, ağır ve göçme hasar durumları için sunulan kırılganlık fonksiyonu dikkate alınmıştır. Bu eğri maksimum yer ivmesinin (PGA) bir fonksiyonu olarak sunulmuştur. Az katli, sünek, özel betonarme yapılara ait Hazus [24]'da tanımlanan kırılganlık eğrisi Şekil 15 'te gösterilmiştir. Yapısal hasar dağılımında PGA, deprem yer hareketi parametresi dikkate alınmıştır.

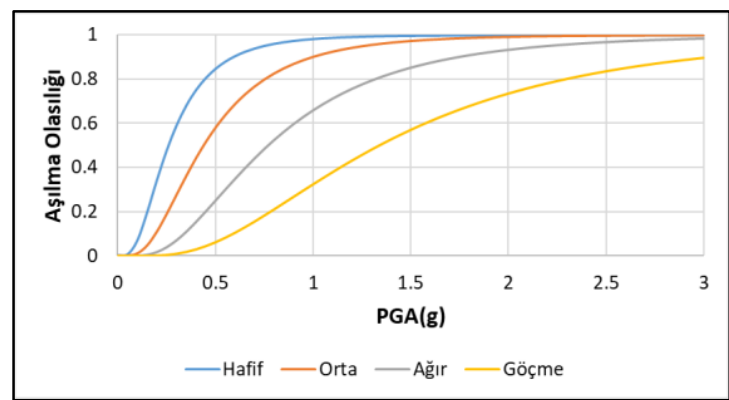

Şekil 15. Dört farklı hasar seviyesi için, az katlı, özel betonarme yapı sınıfına ait dikkate alınan kırılganlık eğrisi [24]

Bir kırılganlık modelinin geliştirilmesi, genellikle kayıp tahmin çalışmasının ilk adımlarındandır. Bir dizi kayıp modelleri için dikkate alınan sonuç modeli, kırılganlık modeliyle birleştirilerek sismik risk değerlendirmesinde kullanılabilmektedir. $\mathrm{Bu}$ çalışmada, HAZUS [24], Askan\&Yücemen (2010) [25], ve Bal ve arkadaşları (2008) [26] tarafindan önerilen sonuç modeli kullanılarak, yapısal elemanlara ait kırılganlı modelleri, kayı modellerine dönüştürülmüştür. Çizelge 1 , bu çalışmada kullanılan hasar durumlarına karşı kayıp oranlarını göstermektedir.

Çizelge 1. Hasargörebilirlik eğrisini oluşturmada kullanılan sonuç modelleri

\begin{tabular}{|l|c|c|c|}
\hline $\begin{array}{l}\text { Hasar } \\
\text { Durumu }\end{array}$ & $\begin{array}{c}\text { Askan \& } \\
\text { Yücemen } \\
(2010)\end{array}$ & $\begin{array}{c}\text { Bal ve } \\
\text { arkadaşları } \\
(2008)\end{array}$ & $\begin{array}{c}\text { Hazus } \\
(1997)\end{array}$ \\
\hline Hafif & 0,05 & 0,16 & 0,02 \\
\hline Orta & 0,30 & 0,33 & 0,10 \\
\hline Ağır & 0,85 & 1,00 & 0,50 \\
\hline Göçme & 0,85 & 1,00 & 1,00 \\
\hline
\end{tabular}

Sismik risk değerlendirilmesinde kullanılan hasargörebilirlik eğrisi, kırılganlık eğrilerinin sonuç modelleriyle (consequence models) birlikte kullanılmasıyla, Eşitlik 1 ile hesaplanmaktadır [27]. Eşitlik 1'de yer alan $I$ deprem şiddet parametresini (PGA, Sa, vb.), $i$, gözönüne alınan deprem şiddet parametresinin değerini, $h d$ her bir hasar durumunu (hafif, orta, ağır, göçme), $K O_{h d}$, her bir hasar durumunda, sonuç modelleriyle elde edilen, ortalama kayıp oranını (loss ratio) (Çizelge 1'de her hasar durumu için farklı sonuç modellerinde, 
ortalama kayıp oranı tanımlanmıştır.) göstermektedir.

E[KayıpOranı $\mid I=i]$; hasargörebilirlik eğrisinde, deprem şiddet parametresinin, $i$ değeri için beklenilen kayı oranını göstermektedir. $E[$ KayıpOranı $\mid I=i]$; deprem şiddet paramteresinin $i$ değerine eşit olduğu anda, tanımlanan 4 farklı hasar durumunda, kırılganlık eğrilerine bağlı olarak, sonuç modellerinde verilen ortalama kayıp oranı hesaba katılarak elde edilmektedir. Eşitlik 1 kullanılarak, ilgili yapıya ait, gözönüne alınan deprem şiddet parametresine bağlı hasargörebilirlik eğrisi elde edilmektedir.

$E[$ KayıpOran $\mid I=i]=\sum_{h d=0}^{n H D}\left(P[H D=h d \mid I=i] . K O_{h d}\right)$

Yapısal elemanlara ait hasargörebilirlik eğrisi, Askan\&Yücemen (2010) [25], Bal ve arkadaşları (2008) [26], ve Hazus (1997) [24] sonuç modeli ve Hazus [24]'dan alınan kırılganlık fonksiyonu Eşitlik (1) içinde kullanılarak, Şekil 16'daki gibi elde edilmiştir.

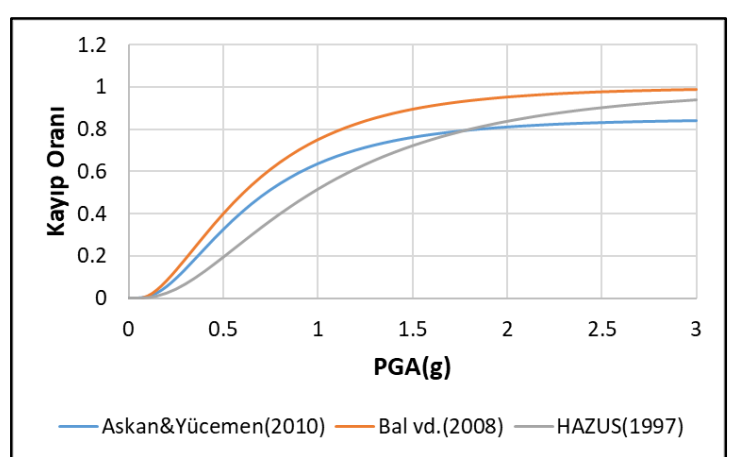

Şekil 16. Dikkate alınan farklı sonuç fonksiyonları için elde edilen hasargörebilirlik eğrileri

Ekonomik kayıplar, hasargörebilirlik eğrilerinin deprem risk analizi modelinde kullanılmasıyla hesaplanmaktadır. Hasargörebilirlik eğrilerinde tanımlanan her bir deprem parametresindeki (PGA) kayıp oranları, bu deprem parametrelerinin deprem tehlikesinden hesaplanan aşılma olasılıklarıyla birlikte kullanılarak, ekonomik kayıpların aşılma olasılıkları tanımlanan zaman aralığı için hesaplanmaktadır. OpenQuake programıla yapılan olasılıksal deprem risk analizi sonucunda yapisal elemanlara ait mali kayıp oranlarının ve kayıp miktarlarının, 50 yılda aşılma olasılığı, zemin bağımlı ve zemin bağımsız durum için Şekil 17 ve Şekil 18 ile gösterilmiştir. Çizelge 2 ve Çizelge 3 'te farklı zemin koşullarında, risk analizinden elde edilen 50 yılda aşılma olasılığ $\% 2$ ve \% 10 olan yer hareketi sonucu oluşabilecek yapısal kayıp oranları verilmiştir.

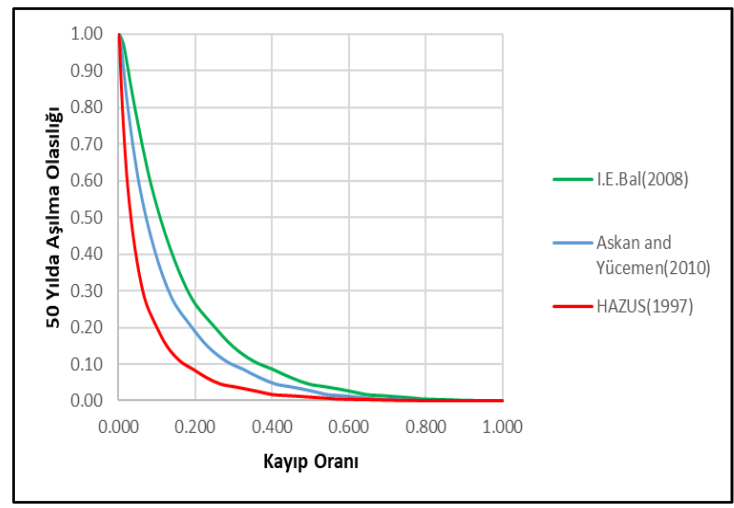

Şekil 17. Yapıya ait risk analizi sonucu elde edilen kayıp eğrileri $\left(\mathrm{V}_{\mathrm{s}, 30}=360 \mathrm{~m} / \mathrm{s}\right)$

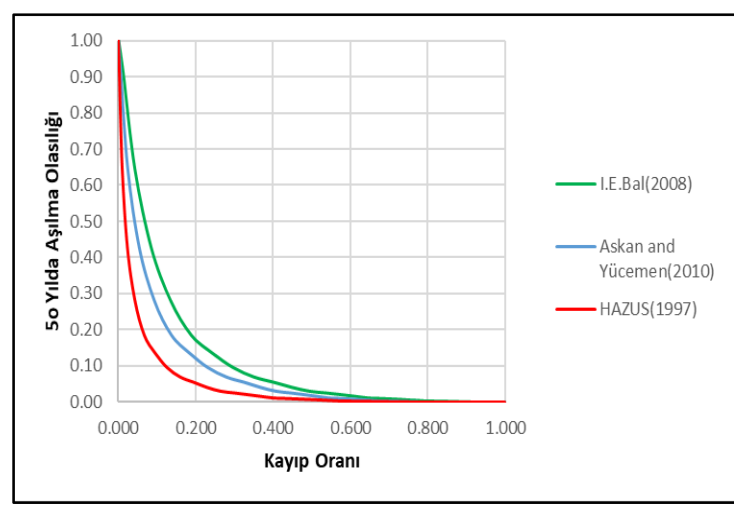

Şekil 18. Yapıya ait risk analizi sonucu elde edilen kayıp eğrileri $\left(\mathrm{V}_{\mathrm{s}, 30}=760 \mathrm{~m} / \mathrm{s}\right)$

Olasılıksal deprem risk analizi sonucunda, Çizelge 2-3'te gösterildiği gibi, zemin bağımlı durum için Ekonomik kayıp oranı en yüksek Bal ve arkadaşları (2008) [26] modelinde hesaplanırken, en düşük Hazus [24] modelinde hesaplanmıştır. Ayrıca, yumuşak zemin $\left(\mathrm{V}_{\mathrm{s}, 30}=360 \mathrm{~m} / \mathrm{s}\right)$ koşullarında, ekonomik kayıpların, sert zemin $\left(\mathrm{V}_{\mathrm{s}, 30}=760 \mathrm{~m} / \mathrm{s}\right)$ koşullarındaki ekonomik kayıplara göre daha fazla olduğu gözlemlenmiştir. 
Çizelge 2. Farklı deprem seviyeleri için yapısal kayıp oranları $\left(\mathrm{V}_{\mathrm{s}, 30}=360 \mathrm{~m} / \mathrm{s}\right)$

\begin{tabular}{|l|c|c|c|}
\hline Deprem Seviyesi & $\begin{array}{c}\text { Askan \& } \\
\text { Yücemen } \\
(2010)\end{array}$ & $\begin{array}{c}\text { Bal ve } \\
\text { arkadaşları } \\
(2008)\end{array}$ & $\begin{array}{c}\text { Hazus } \\
(1997)\end{array}$ \\
\hline DD-1(2475 y11) & 0,80 & 0,90 & 0,60 \\
\hline DD-2(475 y11) & 0,30 & 0,40 & 0,20 \\
\hline
\end{tabular}

Çizelge 3. Farklı deprem seviyeleri için yapısal kayıp oranlar1 $\left(\mathrm{V}_{\mathrm{s}, 30}=760 \mathrm{~m} / \mathrm{s}\right)$

\begin{tabular}{|l|c|c|c|}
\hline $\begin{array}{l}\text { Deprem } \\
\text { Seviyesi }\end{array}$ & $\begin{array}{c}\text { Askan \& } \\
\text { Yücemen } \\
(2010)\end{array}$ & $\begin{array}{c}\text { Bal ve } \\
\text { arkadaşları } \\
(2008)\end{array}$ & $\begin{array}{c}\text { Hazus } \\
(1997)\end{array}$ \\
\hline DD-1(2475 y11) & 0,65 & 0,70 & 0,40 \\
\hline DD-2(475 yı1) & 0,15 & 0,25 & 0,10 \\
\hline
\end{tabular}

\section{SONUÇLAR}

Günümüzde, sosyo-ekonomik hayatın sürdürülmesinde, elektrik üretimi önemli bir role sahiptir. Elektrik şebekeleri, deprem tehlikesinden dolayı hasar görme olasılığı yüksek kritik altyapılardan bir tanesidir. Bu sistemlere ait üretim tesisleri, iletim ve dağıtım ağından herhangi birinde oluşacak aksaklıklar, enerji üretiminde kesintilere sebep olacaktır. Bu durum tesislerin bulunduğu bölgedeki ticari ve endüstriyel faaliyetlerin aksamasına sebep olabilir. Elektrik üretim aşamasında tüm operasyonel faaliyetlerin, otomasyon yöntemi ile kumanda ve kontrol edildiği, üretimin devamlılığının sağlandığı merkez bina, kontrol binasıdır.

$\mathrm{Bu}$ çalışma kapsamında, üretim kapasitesi ve bileşenlerinin detaylı olarak açıklandığı "EnerjiSA Üretim Bandırma-I Doğalgaz Kombine Çevrim Santrali" için deprem tehlike analizi ve tip kontrol binası risk değerlendirmesi, söz konusu alanının tektonik yapısı, depremselliği ve sismik kaynak bölgelemesi göz önüne alınarak, açı kaynaklı bir program olan OpenQuake kullanılarak gerçekleştirilmiştir. Bunun için, santralin bulunduğu bölgeye özel olarak değerlendirilen olasılıksal deprem tehlike analiz sonuçları kullanılmıştır. Hasar ve kayıp değerlendirilmesinde ise yapıya ait Hazus'da sunulan kırılganlık eğrisi dikkate alınarak, üç farklı hasargörebilirlik modeli kullanılmıştır. Ayrıca, ekonomik kayıp, zemin bağımlı ve zemin bağımsız durum için değerlendirilmiş̧tir.

Olasiliksal deprem tehlike analizinden elde edilen sahaya özel deprem yer hareketi spektrumları, DBYBHY 2007 ve TBDY-2018 standart deprem yer hareketi spektrumu ile karşılaştırılmıştır. DD-1 ve DD-2 deprem seviyesinde, ZB zemin koşulu için olasılıksal tehlike analizi sonucunda elde edilen spektrum, sismik tasarımda kullanılması geçerli olurken, ZD zemin koşulları için bölgede TBDY2018 tasarım spektrumunun kullanılmas1 gerekmektedir.

Olasilıksal deprem risk analizi sonucunda, zemin bağımlı ve bağımsız durumlarda tehlikenin herhangi bir aşılma olasılığı için en yüksek kayıp oranı Bal ve arkadaşları [26] modelinde hesaplanırken, en düşük Hazus [24] modelinde hesaplandığ 1 gözlenmiştir. Askan\&Yücemen [25] modeli dikkate alınarak elde edilen kayıp oranları incelendiğinde ise üç modelin ortalama değerlerine yakın olduğu gözlemlenmiştir. Ayrıca, tehlikenin her aşılma olasılı̆̆ında, zayıf zemin koşullarında elde edilen kayıp oranları daha yüksek çıkmaktadır. Tehlikenin farklı aşılma olasılıklarında bu fark değişmektedir. Örneğin 50 yılda aşılma olasıllı̆ $\% 10$ olan tehlike durumunda zayıf zemin koşullarında elde edilen kayıp oranları yaklaşık 2 katı arttı̆̆ gözlemlenmiştir.

Çalışma kapsamında sunulan kayıp eğrileri, EnerjiSA Üretim Bandırma-I DGKÇS'nin deprem sonrası eylem planlarının geliştirilebilmesi ve Enerji Santralleri için en kritik konulardan biri olan; oluşabilecek üretim kaybı süresinin öngörülebilmesi konusunda önemli veriler sağlamaktadır. $\mathrm{Bu}$ çalışmanın devamında elde edilen sonuçlar kullanılarak, kontrol binasının yapısal hasarından dolayı üretimin kesintiye uğrama süresi çalışılabilecektir.

\section{KAYNAKLAR}

1. Massie, A., Watson, N.R., 2011. Impact of the Christchurch Earthquakes on the Electrical Power System Infrastructure. Bulletin of the New Zealand Society for Earthquake Engineering, 44(4), 425-430. 
2. Watson, N.R., 2010. Impact of the Darfield Earthquake on the Electrical Power System Infrastructure. Bulletin of the New Zealand Society for Earthquake Engineering, 43(4), 421-424.

3. Eidinger, J., Davis, C., Tang, A., Kempner, L., 2012. 9.0M Tohoku Earthquake, March 11, 2011, Performance of Water and Power Systems, http://www.geengineeringsystems. $\mathrm{com} /$.

4. Eidinger, J., Tang, A., O'Rourke, T., 2010. Technical Council on Lifeline Earthquake Engineering (TCLEE), Report of the 4 September 2010 Mw 7.1 Canterbury (Darfield), New Zealand Earthquake. In American Society of Civil Engineers, 1-49.

5. Giovinazzi, S., Wilson, T.M., Davis, C., Bristow, D., Gallagher, M., Schofield, A., Tang, A., 2011. Lifelines Performance and Management Following the 22 February 2011 Christchurch Earthquake, New Zealand: Highlights of Resilience.

6. Transpower (2011a). 4 September 2010 Darfield Earthquake. Lessons Learned. Transpower New Zealand Limited Internal Report, 30 March 2011.

7. Transpower (2011b). 22 February 2011 Christchurch Earthquake Key Findings and Lessons Learned. Transpower New Zealand Limited Internal Report, 30 June 2011.

8. Howard, S., Riker, C., Knight, B., Knoles, S., 2015. Innovative Analysis and Seismic Retrofit of $500 \mathrm{kV}$ Flexible Bus Substation Support Structures. In Electrical Transmission and Substation Structures 2015, 438-451.

9. Shinozuka, M., Dong, X., Jin, X., Cheng, T.C., 2005. Seismic Performance Analysis for the Ladwp Power System. In 2005 IEEEPES Transmission \& Distribution Conference \& Exposition Asia and Pacific, 1-6.

10. Park, J., Nojima, N., Reed, D.A., 2006. Nisqually Earthquake Electric Utility Analysis. Earthquake Spectra, 22(2), 491-509.

11. Buriticá Cortés, J.A., Sánchez-Silva, M., Tesfamariam, S., 2015. A Hierarchy-based Approach to Seismic Vulnerability Assessment of Bulk Power Systems. Structure and Infrastructure Engineering, 11(10), 1352-1368.
12. Kwasinski, A., Eidinger, J., Tang, A., TudoBornarel, C., 2014. Performance of Electric Power Systems in the 2010-2011 Christchurch, New Zealand, Earthquake Sequence. Earthquake Spectra, 30, 205-230.

13. Yesilyurt, A., Okuyan Akcan, S., Zulfikar, A., 2021. Rapid Power Outage Estimation for Typical Electric Power Systems in Turkey. Challenge Journal of Structural Mechanics, 7(2), 84-92.

14. Holmgren, A.J., Molin, S., 2006. Using Disturbance Data to Assess Vulnerability of Electric Power Delivery Systems. Journal of Infrastructure Systems, 12(4), 243-251.

15. Martins, L., Silva, V., 2020. Development of a Fragility and Vulnerability Model for Global Seismic Risk Analyses. Bull. Earthq. Eng.

16. Silva, V., Crowley, H., Pagani, M., Modelli, D., Pinho, R., 2013b. Development of the OpenQuake Engine, the Global Earthquake Model's Open-source Software for Seismic Risk Assessment, Natural Hazards.

17. Pinho, R., 2012. GEM: A Participatory Framework for Open, State-of-the-art Models and Tools for Earthquake Risk Assessment Worldwide. In: Proceedings of the $15^{\text {th }}$ World Conference on Earthquake Engineering, Lisbon, Portugal.

18. Cornell, C.A., 1968. Engineering Seismic Risk Analysis. Bull Seismol Soc Am 58, 1583-1606.

19. Yönetmeliği, TD. 2007. Deprem Bölgelerinde Yapılacak Binalar Hakkında Yönetmelik. T.C. Çevre ve Şehircilik Bakanlığı, Afet İşleri Genel Müdürlüğü, Deprem Araştırma Dairesi.

20. TBDY-2018, Deprem Etkisi Altında Binaların Tasarımı İçin Esaslar, http://www.resmigazete. gov.tr/eskiler/2018/03/20180318M1-2-1.pdf, 416, 2018.

21. Woessner, J., Laurentiu, D., Giardini, D., Crowley, H., Cotton, F., Grünthal, G., Valensise, G., Arvidsson, R., Basili, R., Demircioglu, M.B., Hiemer, S., Meletti, C., Musson, R.W., Rovida, A.N., Sesetyan, K., Stucchi, M., 2015. The 2013 European Seismic Hazard Model: Key Components and Results, Bulletin of Earthquake Engineering, 13, 3553-3596. https://doi.org/10.1007/s10518015-9795-1. 
22. Chiou, B.J., Youngs, R.R., 2008. An NGA Model for the Average Horizontal Component of Peak Ground Motion and Response Spectra. Earthquake Spectra, 24(1), 173-215.

23. FEMA 356 (Federal Emergency Management Agency), 2000. NEHRP Guidelines for the Seismic Rehabilitation of Buildings. Washington DC.

24. FEMA (Federal Emergency Management Agency), 2003. HAZUS-MH Technical Manual. Washington DC:

25. Askan, A., Yucemen, M.S., 2010. Probabilistic Methods for the Estimation of Potential Seismic Damage: Application to Reinforced Concrete Buildings in Turkey, Struct. Saf., 32(4), 262-271.

26. Bal, İ.E., Crowley, H., Pinho, R., Gülay, F.G., 2008. Detailed Assessment of Structural Characteristics of Turkish RC Building Stock for Loss Assessment Models, Soil Dynamics and Earthquake Engineering, 28(10-11), 914-932.

27. Martins, L., Silva, V., Marques, M., Crowley, H., Delgado, R., 2016. Development and Assessment of Damage-to-loss Models for Moment-frame Reinforced Concrete Buildings. Earthquake Engineering \& Structural Dynamics, 45(5), 797-817. 